\title{
Development of WAP Based Students Information System in Campus Environment
}

\author{
Mohd Nazri Ismail
}

\begin{abstract}
In this paper, we introduce a novel approach to sharing information between students and lecturers in order to enhance quality of information in campus environment via WAP technology. We describe a network for distributing campus information among lecturers and students. The concept of developing campus information via WAP technology is to ensure that student can access information at any time, at any locations. WAP Based Students Information System helps the students and lecturers on campus to find and access information based on ad-hoc basic, which is of interest and relevant to students or lecturers; they only need a PDA or a mobile phone. This paper describes the campus environment has been adapted for use on the new generation of WAP-enabled Internet devices such as PDA and mobile phones to access ad-hoc information. The results and analysis show that based on framework the WAP-based customized information services have successfully performed in campus environment. Therefore, campus institutions can provide and offer information for mobile users (students) as value added services.
\end{abstract}

Index Terms - WAP, Campus, PDA, Information, Students

\section{INTRODUCTION}

WAP Based Students Information System is a WAP application that allows students and lecturers to retrieve related information by using a WAP enabled handheld device. This study focuses on the development of a mobile browser in campus environment that supports WAP as well as Web service. The system will help students to check their academic result and related courses information, view the own personal information, check for announcement, and even courses registration. It performs managing student's information system in the wireless environment. Students will be provided with more value-added services, which are easy to use directly from a mobile phone to access information at any time, at any locations. The current issues are: i) information can not be access at any time, at any locations (not mobility); and ii) registration and result need to collect at main campus. This study is to improve the convenience for the student information retrieval. Deployment of campus information-oriented applications for mobile terminals, the wireless application protocol (WAP) has provided a promising solution. The results and

Mohd Nazri Ismaiis with Faculty of MIIT, University Kuala Lumpur (UniKL), MALAYSIA). analysis show that based on framework the WAP-based information services have successfully performed for campus mobility environment. In addition, it is convenient to access online information via mobile device between students and lecturers. The students

and lecturers can immediately access information about the campus news and save the time spent on reading large amount of electronic documents. WAP technology will continue to play an important role in the development of information services. In this paper, we emphasize the importance of providing customized information services for mobile students.

\section{RELATED WORKS}

Smart terminal equipments such as mobile phone, PDA etc., develop quickly at present [1]. Wap provides a viable technical solution for wireless data terminal applications. Wireless network has many characteristics, for example, it can be visited conveniently and fast, accessed anytime and anywhere. Therefore we want to focus on benefits, more specifically on the benefits that are associated with the use of mobile services. Mobile devices and services offer people the opportunity to move around while maintaining access to relevant services and staying (socially) connected [2]. The nomadic value of mobile services is reflected in concepts like anytime and anyplace [3].

Pagani [4] mentions mobility, availability (anytime, anyplace), and personalization as important benefits of (multimedia) mobile services. m-Learning may provide tools to respond to the demands of working life and information society [16]. One way to enhance m-Learning is to raise the usability of mobile terminals as good usability is the basis for the meaningful and effective learning [5]. WAP sites have been developed with Wireless Markup Language (WML). Meanwhile, to translate Hypertext Markup Language (HTML) pages into proper WML ones become so imperative since it is difficult for WAP users to read most contents designed for PC users via their mobile phone screens [6].

Most handheld devices have already been equipped with a web browser. A mobile browser can become a powerful platform for playing a variety of digital media contents, improving the current situation where service providers need to prepare their own players for many different types of media contents [15]. Table 1 is a summary of the current mobile browsers found in the market $[7,8,9,10,11,12]$. 
One popular approach to developing mobile browsers is to adapt desktop browsers to mobile/wireless environments. In the early years of WAP era, WML1, which includes WML
1.0, 1.1, 1.2, and 1.3, was the mark-up language used for creating mobile contents (see Table 1). Following WML 1.x, WAP 2.0 introduced XHTML MP [13] and WAP CSS [14].

TABLE 1: SUMMARY OF MOBILE BROWSERS

\begin{tabular}{|c|c|c|c|c|c|c|c|}
\hline & Platform & $\begin{array}{l}\text { Cost/Open } \\
\text { source }\end{array}$ & $\begin{array}{l}\text { Layout } \\
\text { engine }\end{array}$ & WAP supports & HTML & $\begin{array}{c}\text { Styleshee } \\
\text { t }\end{array}$ & Scripting \\
\hline Wapsilon 2.4 & Web-based & Free & $\mathrm{N} / \mathrm{A}$ & WAP1.3 & No & No & No \\
\hline WinWap & $\begin{array}{l}\text { Windows | } \\
\text { Pocket PC }\end{array}$ & $\$$ & N/A & $\begin{array}{c}\text { WML 1.3 } \\
\text { WMLScript 1.2.1 }\end{array}$ & No & No & No \\
\hline Opera mobile & $\begin{array}{l}\text { PocketPC | E- } \\
\text { linux | Symbian }\end{array}$ & $\$$ & Presto & $\begin{array}{c}\text { XHTML MP | } \\
\text { WML1.x | cHTML }\end{array}$ & HTML 4.01 & $\mathrm{CSS} 2$ & $\begin{array}{c}\text { ECMAScript } \\
3^{\text {rd }} \\
\end{array}$ \\
\hline NetFront 1.3 & $\begin{array}{c}\text { PocketPC | E- } \\
\text { Linux | PalmOS | } \\
\text { Symbian }\end{array}$ & $\$$ & N/A & $\begin{array}{c}\text { XHTML Basic | } \\
\text { cHTML | WML } 1.3 \mid \\
\text { I-mode }\end{array}$ & HTML 4.01 & \begin{tabular}{|c} 
JavaScrip \\
t 1.5
\end{tabular} & $\mathrm{CSS} 2$ \\
\hline Embider & Wipi phones & $\$$ & $\mathrm{~N} / \mathrm{A}$ & \begin{tabular}{|l|l|} 
WAP $1 . \mathrm{x}$ & WAP 2.0 \\
\end{tabular} & HTML 4.01 & $\mathrm{CSS} 2$ & Jscript \\
\hline Nokia S60 & S60 phones & Open source & KHTML & XHTML 1.0 & HTML & CSS & ECMAScript \\
\hline MiniWap & WinCE $\mid$ E-Linux & $\mathrm{N} / \mathrm{A}$ & Gecko & $\begin{array}{c}\text { WML 1.x | XHTML } \\
\text { MP | WCSS }\end{array}$ & HTML 4.01 & $\mathrm{CSS} 2$ & JavaScript 1.5 \\
\hline
\end{tabular}

\section{METHODOLOGY AND SYSTEM ARCHITECTURE}

Figure 3.1 shows the overall framework of the WAP service implementation in campus environment. There are four phases development process such as: i) Web server; ii) WAP gateway; iii) WAP content/server; and iv) link to existing campus network/Internet/GSM/3G. The network architecture design of the campus WAP Based Students Information System, consists of two-system architecture: i) existing web server network; and ii) new implementation of WAP service. Students and lecturers can access information via traditional Web service or WAP service (see Figure 3.2 and Figure 3.3).

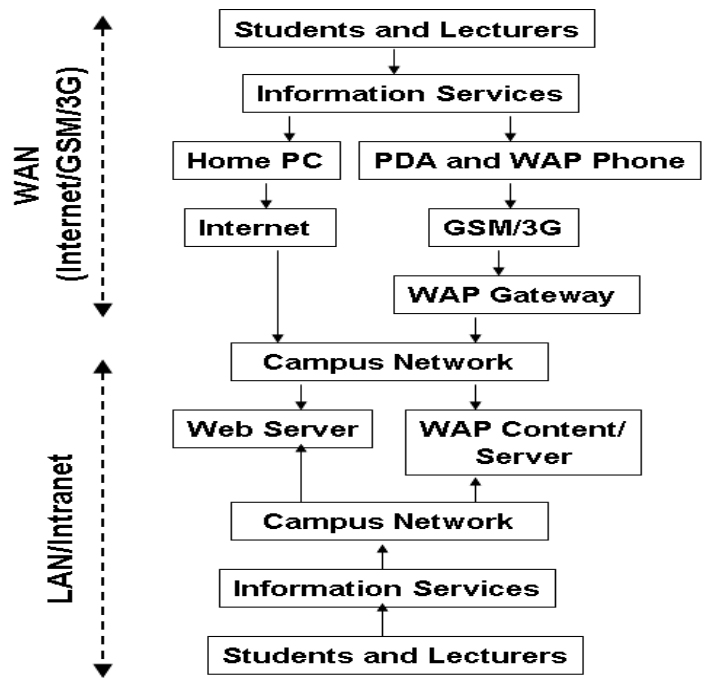

Figure 3.1: Framework of WAP Service Implementation
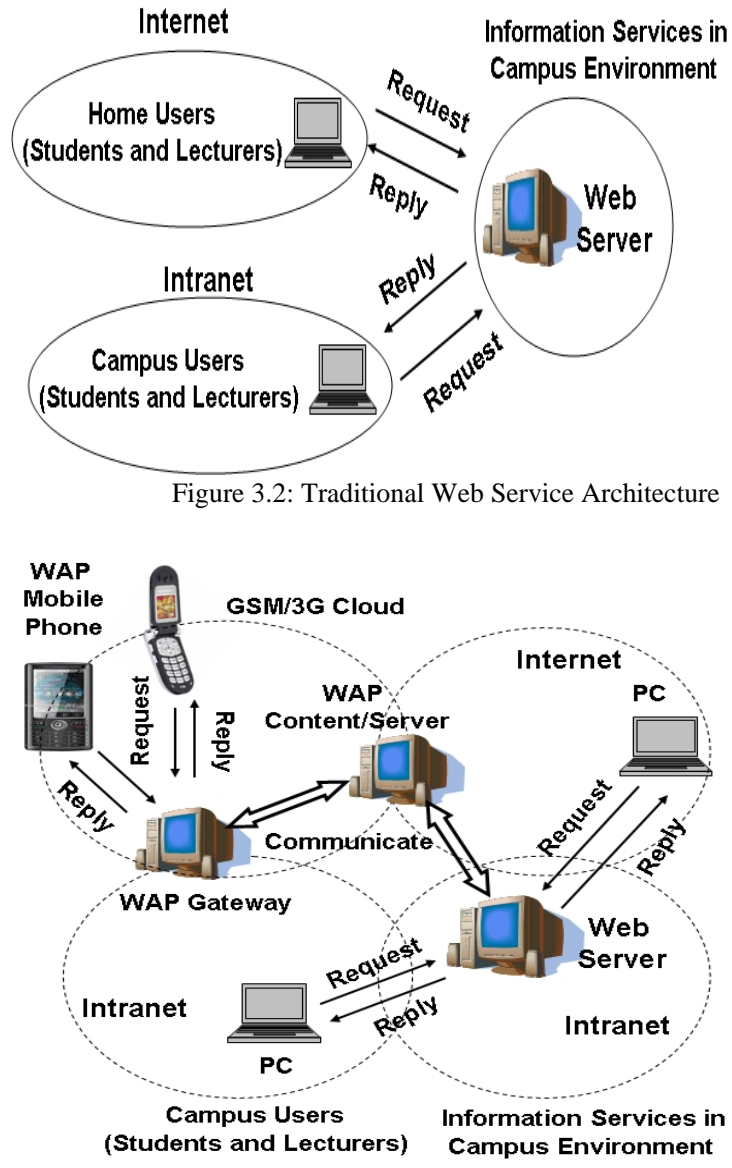

Figure 3.3: Convergence of WAP and Web Service Architecture

\section{CASE DIAGRAM AND ACTOR}

Use Case Diagram: Use case diagrams are used to show the functionality that the system will provide and to show which user will communicate with the system in some way to use the functionality. Use case diagrams show three aspects of the system: actor, use case, and the system/subsystem boundary. There are three types of relationships that can be applied in a use case diagram:

- Generalization relationships between actors

- Dependency and generalization relationships between use cases

- Association relationships between actors and use cases 
Use Case and Actor: A use case is a sequence of actions that an actor performs within a system to yield an observable result of value or achieve a particular goals. An ellipse represents a use case. An actor represent a role that user or entity, such as another system or database which need to interact with the system for information exchange purpose. An actor is represented by a stick man figure. The figure below shows an example of an actor called Administrator interacting with use case called Login (see Figure 4.1).

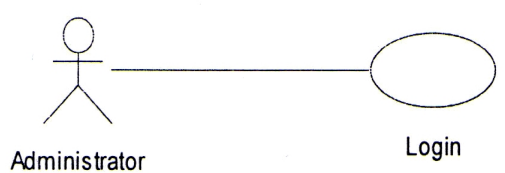

Figure 4.1: Case and Actor

Actor Listing: Actor is a person or a system that interacts with a system, so all actors should be identified first. The following table identifies the actors of WAP Based Students Information System. The two use case diagrams shown in Table 4.1 imply the student and administrator application on the proposed system.

Table 4.1: Actor of the proposed system

$\begin{array}{ll}\begin{array}{l}\text { Actor } \\ \text { Administrator }\end{array} & \begin{array}{l}\text { Description } \\ \text { User of the module who involving in } \\ \text { access control of the system and the data } \\ \text { maintenance for all the modules }\end{array} \\ \text { Student } & \begin{array}{l}\text { Users of the system who involving only } \\ \text { in enquiring information and registering } \\ \text { courses }\end{array}\end{array}$

Sequence Diagram: Sequence diagrams are an easy and intuitive way of describing the behaviour of a system by viewing the interaction between the system and its environment. A sequence diagram shows an interaction arranged in a time sequence. It shows the objects participating in the interaction by their lifelines and the message they exchange, arranged in a time sequence. A sequence diagram has two dimensions: the vertical dimension represents time; the horizontal dimension represents different objects. The vertical line is called the object's lifeline. The lifeline represents the object's existence during the interaction. An object is shown as a box at the top of a dashed vertical line. An arrow between the lifelines of two objects represents each message. The order in which these messages occur is show top to bottom on the page. Each message is labelled with the message name. The label also can include the argument and some control information and show self-delegation, a message that an object sends to itself, by sending the message arrow back to the same lifeline. The horizontal ordering of the lifelines is arbitrary. A sequence diagram is an alternative way to understand the overall flow of the control of a program. Sequence diagram can be used to quickly understand the sequence of the system. Figure 4.2, Figure 4.3, Figure 4.4 and Figure 4.5 show the sequence diagrams of WAP Based Information System in campus environment based on active account, login, view course information, check result and view personal profile.

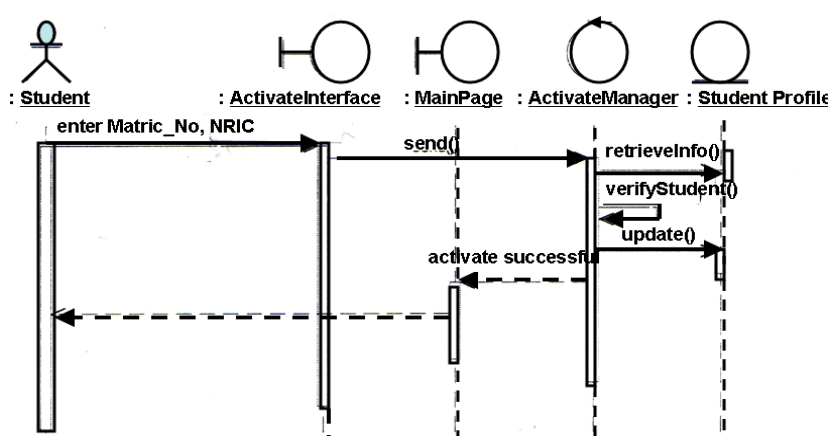

Figure 4.2: Sequence Diagram of "Active Account"

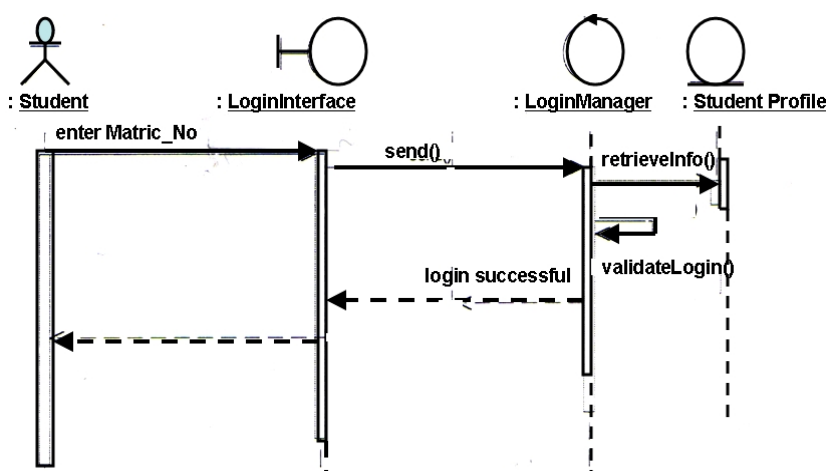

Figure 4.3: Sequence Diagram of "Login"

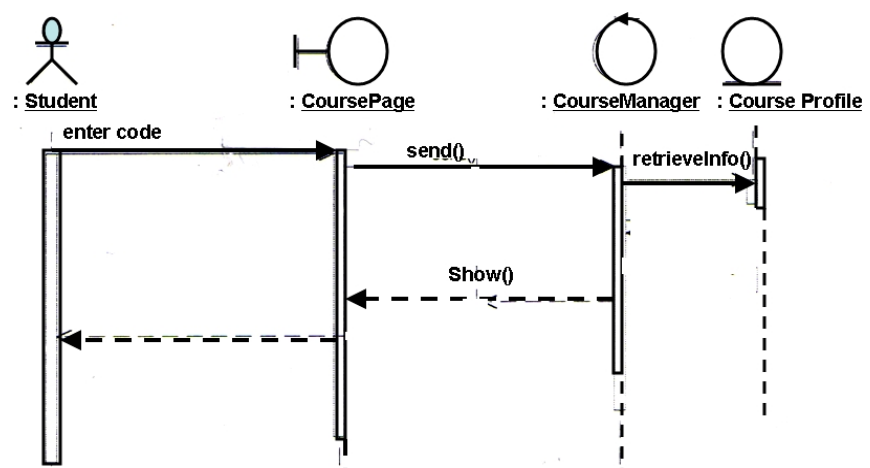

Figure 4.4: Sequence Diagram of "View Course Information"

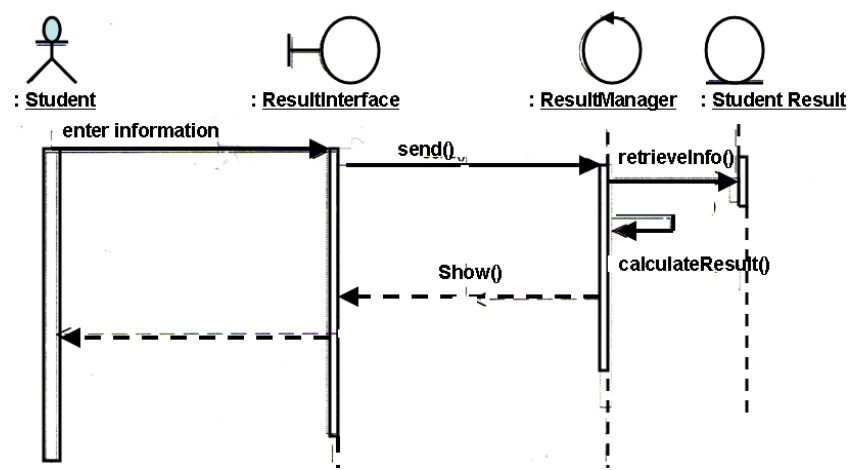

Figure 4.5: Sequence Diagram of "Check Result"

\section{ENTITY RELATIONSHIP MODEL FOR WAP AND WEB}

WAP-based Students' Information System uses the relational database model in its implementation. The 
relational model represents all data in database as simple two dimensional tables called relations. Relational model can relate data in any one file or table to data in another file or table as long as both tables share a common data element. The entity diagram is frequently used to logically represent the connection between data and entity within system. The ER Diagram assists in defining the data processing and requirement constraint that lie ahead. It helps the implementation of the database and interprets different views of data from different perspectives (see Figure 5.1).

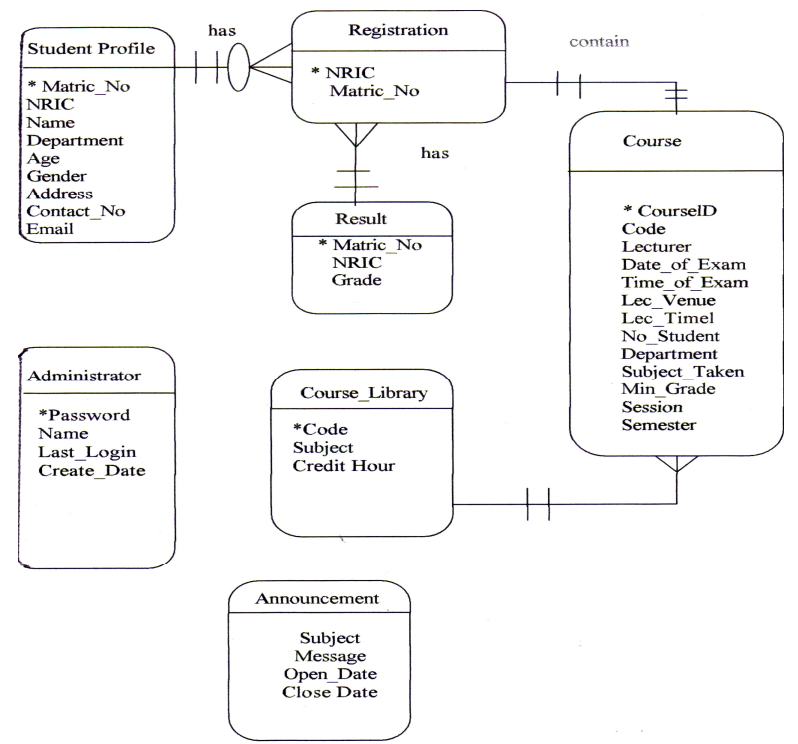

Figure 5.1: Entity Relationship Diagram

\section{RESULTS OF WAP SERVICE}

We have setup a WAP service environment to retrieve information at University of Kuala Lumpur in Malaysia based on mobility approaches. The main objectives of this convergence technique between WAP and Web as follow: i) provide an easier method to access information; ii) provide a WAP based information retrieval system to build an information system that could be available to the students at any location; and iii) provide easy key access and menu-driven interface. Figure 6.1 shows the current Web-base Students' Information System. We have converged WAP and Web service to ensure that students are able to access student information system at anytime and at any location. Figure 6.2 shows the design of the campus WAP Based Students Information System that consists of three-system modules: i) student; ii) course; iii) personal record information and iv) announcement. The WAP Based Students Information System is also provided a security system, therefore, students need to key-in their 'ids' and 'password' (see Figure 6.3). In addition, students are able to display their profile (see Figure 6.4). Students are also able to register (add, delete, modify) their semester subject through WAP Based Students Information System and access their semester result from everywhere using PDA or mobile phone (see Figure 6.5 and Figure 6.6). Menu driven interface will apply in the system to minimize text entry by keypad. The selection menus are well categorized in order to assist the student and navigate the application.

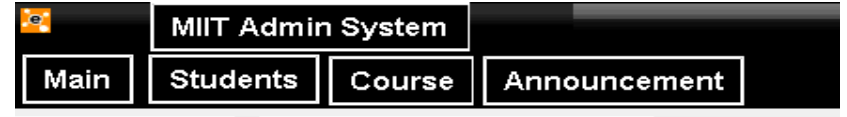

Announcement Wed, 02-Apr-2008, 13:05:01

Login Time

Wed, 02-Apr-2008, 13:05:01

Statistics

\begin{tabular}{ll}
\hline Students & 2 \\
Courses & 3 \\
Announcements & 2 \\
Users & 2
\end{tabular}

Copyright (c) 2008 MIIT. All rights reserved. Terms of Use

Figure 6.1: Web-base Students' Information System

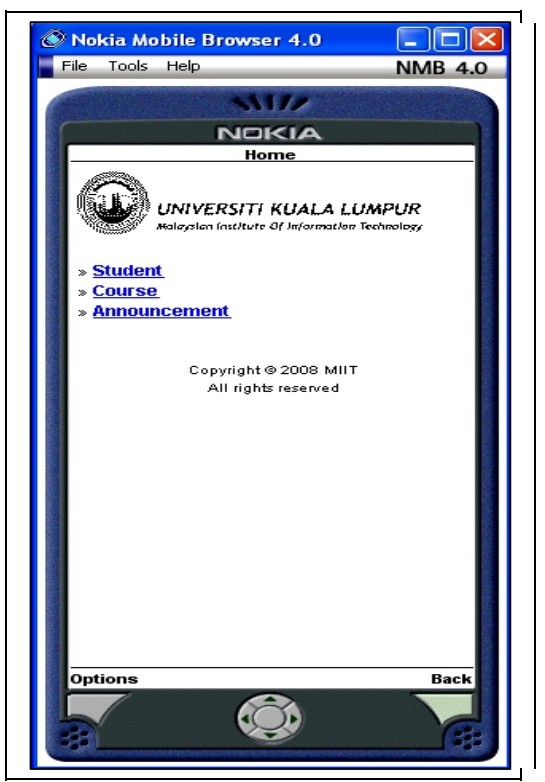

Figure 6.2: Student Main Menu

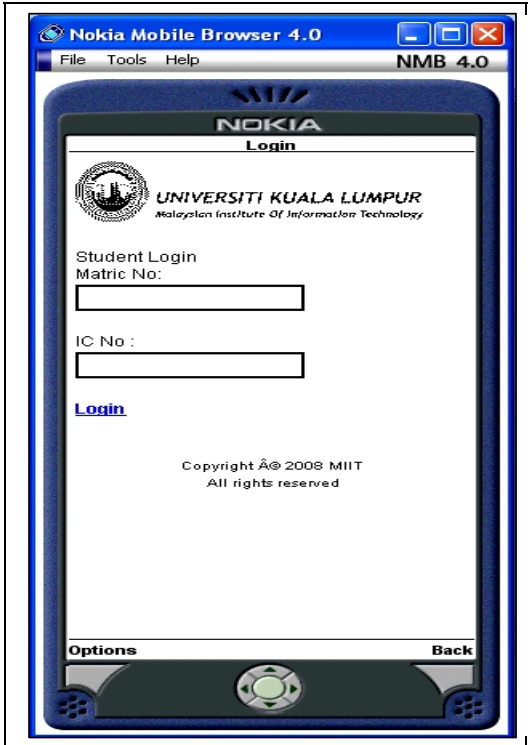

Figure 6.3: Student Login Page (Security Purpose) 


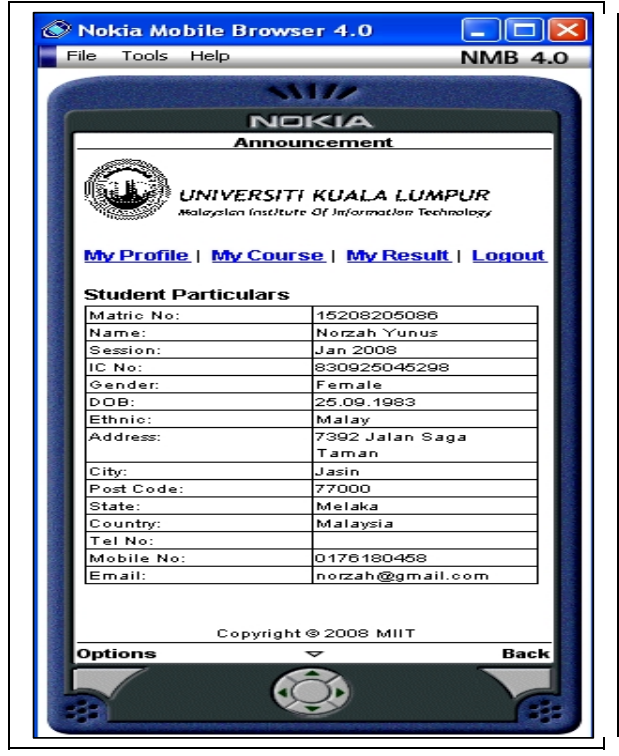

Figure 6.4: Student Profile Layout

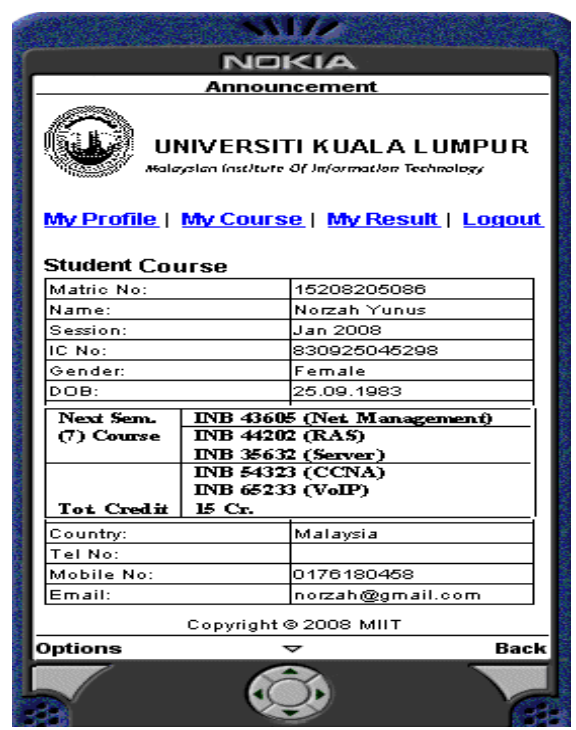

Figure 6.5: Subject Registration via WAP Service

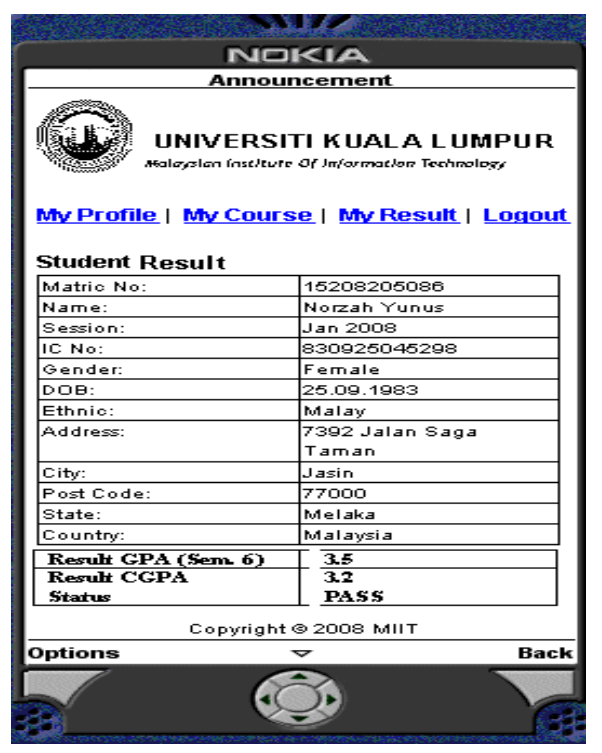

Figure 6.6: Display Student Result

\section{CONCLUSION}

In this paper, we presented WAP Based Students Information System, a mobile WAP browser for handheld devices. This study focuses on the development of a mobile browser in campus environment that supports WAP as well as Web service. It is clear that there is a need for development for mobile services and terminals in campus environment and students are able to retrieve information at anytime and at any location. The practical value of mobility in teaching will be greater in the future because mobile terminals are flexible to use and they enable real time and place independence. A key question in applying mobile terminals to campus environment is easiness of usage. Thus one way to enhance m-Information is to raise the usability of mobile terminals. Based on the results, it shows that WAP Based Students Information System enabled mobile students to enjoy much valuable information and a large number of services over mobile networks. This WAP application provides students to request the academic information using wireless devices. By using this application, students are able to request and retrieve their examination result, view their profile, check announcement and register course. The system can be further enhanced to become a more powerful and sophisticated system. There are still many aspects for improvement and enhancements of the system can be made in the future to meet changing needs of the students. Therefore, enhancement in the future will extend the usability of this WAP Based Student Information System. The system limitations should be improved to enhance the functionalities. There are several enhancements that could extend the usability of the developed system such as reporting module, linked with other faculties' student information system, SMS Messaging, Online Help File and Demonstration Help System.

\section{REFERENCES}

[1] Xia S., Yuan G., Zhang L., Deng Z., Xiao J. 2007. "Study on Wap Self-Adapt Based on Web Usage Mining”. 2008 ISECS International Colloquium on Computing, Communication, Control, and Management, pp. 605-609.

[2] Open Mobile Alliance, 2001. WAP CSS Specification, http://www.wapforum.org/tech/documents/ WAP-239-WCSS20011026-a.pdf, accessed 20/9/08.

[3] Harry B., Christer C., Francisco J. Molina-Castillo. 2007. "From WAP Services to Mobile Video: Trends in Mobile Services in Finland". International Conference on the Management of Mobile Business (ICMB 2007), pp. 33.

[4] Pagani, M. 2004. "Determinants of Adoption of Third Generation Mobile Multimedia Services". Journal of Interactive Marketing, Vol. 18, no. 3, pp. 46-59.

[5] Kristian K. 2002. "Evaluating WAP Usability: "What Usability?"', IEEE International Workshop on Wireless and Mobile Technologies in Education (WMTE'02), pp. 169.

[6] Gwo-Jen H., Judy C.R. T., Yu-San H. 2002. "I-WAP: An Intelligent WAP Site Management System", IEEE Transactions on Mobile Computing, April-June 2002 (Vol. 1,No. 2), pp. 82-95.

[7] WAPSILON, Wapsilon web-based WAP browser, http://www.wapsilon.com, accessed 12/8/2008.

[8] WinWap Technologies, WinWap browser, http://www.wap-proof.com/, accessed 19/9/2008

[9] Opera software, Opera for Mobile, http://www.opera.com/products/mobile/, $\quad$ accessed $3 / 10 / 2008$

[10] Access. Co. Ltd, NetFront browser, http://www.accesscompany.com/products/ netfrontmobile/index.html, accessed 23/7/2008 
[11] Infraware,

Embider

browser, http://www.infraware.co.kr/eng/main.asp accessed 21/8/2008.

[12] Nokia, http://opensource.nokia.com/projects/S60browser/, accessed 11/10/2008.

[13] Kaikkonen, A. and Roto, V. 2002. "XHTML in Mobile Application Development". In Proceedings of the 4th international Symposium on Mobile Human-Computer interaction (September 18 - 20,2002). F. Paternò, Ed. Lecture Notes In Computer Science, vol. 2411. Springer-Verlag, London, 344-348.

[14] Vu H. K., Kibong K, Keung H. L. 2007. "MiniWap: Navigating WAP with Minimo". 31st Annual International Computer Software and Applications Conference - Vol. 2- (COMPSAC 2007), pp. 63-68

[15] Jarvenpaa, S.L., K.R. Lang, Y. Takeda \& V. Tuunainen. 2003. "Mobile Commerce at Crossroads". Communications of the ACM. Vol. 26, no. 12, pp. 41- 44. 